\title{
Is Immunosuppressive and Thrombolytic Therapy Really Effective in a Patient With Intracardiac Thrombosis and Pulmonary Artery Aneurysm due to Behçet's Disease?
}

\author{
Nükhet ALADAĞ ÇİFTDEMİR ${ }^{1}$, Selman GÖKALP ${ }^{2}$, Tuba EREN ${ }^{1}$, \\ ${ }^{1}$ Department of Pediatrics, Trakya University Faculty of Medicine, Edirne, Turkey \\ ${ }^{2}$ Department of Pediatrics, Cerrahpaşa University Faculty of Medicine, Istanbul, Turkey
}

\begin{abstract}
Behçet's disease (BD) is a rare, multisystemic, chronic vasculitic disorder with unknown etiology. Intracardiac thrombus formation and pulmonary artery aneurysm in BD are very rare. The treatment protocol in patients with vascular involvement, particularly those with pulmonary artery aneurysm accompanied by thrombosis, have not been clearly defined. In this article, we report an exceptional case, who had been treated unsuccessfully with a combination of anti-inflammatory/immunosuppressive therapy and thrombolytic agents, to discuss the poor prognosis of pulmonary artery aneurysm accompanying intracardiac thrombosis in juvenile BD.

Keywords: Behçet's disease, intracardiac thrombosis, pulmonary artery aneurysm.
\end{abstract}

Behçet's disease (BD) is a rare, multisystemic, chronic vasculitic disorder with unknown etiology. The most common signs of $\mathrm{BD}$ are recurrent aphthous oral ulcers, genital ulcers, ocular lesions, dermatological lesions, and arthritis., ${ }^{1,2}$ BD may also affect the pulmonary and cardiovascular systems. ${ }^{2-4}$ Frequency of BD is low but intracardiac thrombus (IcT) formation is even less common; this serious complication has been reported only as case reports. ${ }^{5-7}$ Pulmonary artery aneurysm (PAA) is also very rare, and only a few pediatric patients have been reported in the literature. ${ }^{6,7}$ IcT accompanying PAA is extremely rare in the pediatric age group. In this article, we present an unusual case of an adolescent patient with PAA and IcT who did not survive despite all medical therapies.

\section{CASE REPORT}

A 16-year-old male patient was admitted to the hospital with complaints of productive cough, fever, and chills. Despite oral amoxicillin/ clavulanic acid treatment, the patient's complaints increased; he developed shortness of breath and was admitted to another hospital. The patient had weight loss of $8 \mathrm{~kg}$ in the prior three months. Two years before admission, the patient was suspected to have $\mathrm{BD}$ because of recurrent anterior uveitis and treated with infliximab. The patient never developed oral or genital ulcers, arthralgia, or neurological complaints during follow-up. There was no family history of BD or consanguinity. A written informed consent was obtained from the parents of the patient.

Received: September 08, 2018 Accepted: February 23, 2019 Published online: April 30, 2019

Correspondence: Nükhet Aladağ Çiftdemir, MD. Trakya Üniversitesi Tıp Fakültesi Çocuk Sağlığı ve Hastalıkları Anabilim Dalı, 22030 Edirne, Turkey. Tel: +90 533 - 3113800 e-mail: nukhetaladag@trakya.edu.tr 


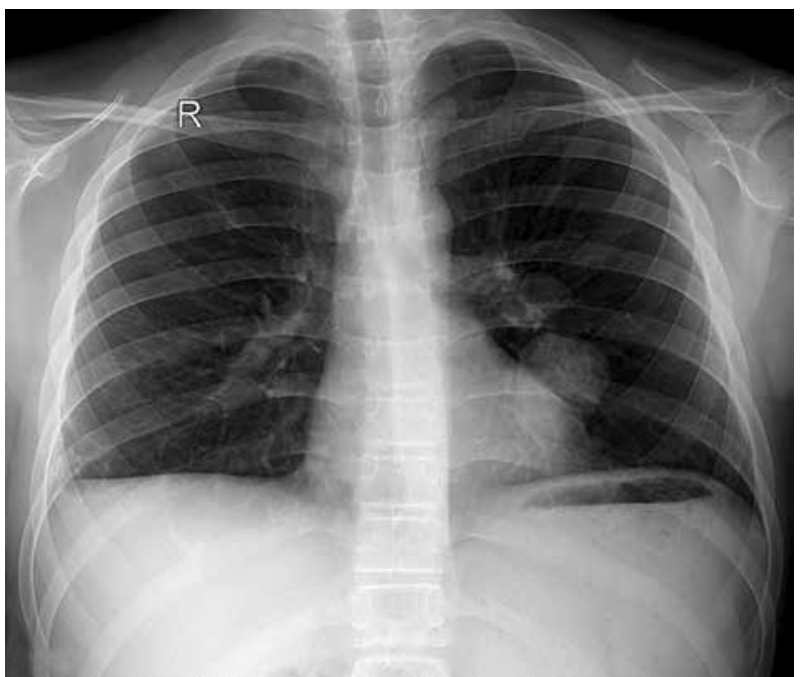

Figure 1. Chest radiograph in admission showing a large, left parahilar mass and peripheral infiltration.

On admission, body temperature was $38.5^{\circ} \mathrm{C}$. The patient had tachypnea, dyspnea, tachycardia, decrease of breath sounds in the basal regions of both lungs, and few crackling rales were heard in the left lung field. There was nearly total loss of vision in the right eye and $40 \%$ loss of vision in the left eye. Chest radiograph revealed a large left parahilar mass and peripheral infiltration (Figure 1). Computed tomography (CT) angiogram revealed two aneurysmal dilatations originating from the intraparenchymal branches of the left pulmonary artery $(18 \times 26 \mathrm{~mm}, 31 \times 20 \mathrm{~mm})$. Peripheral infarct areas were seen in basal fields of both lungs, and pulmonary embolism was present in the intraparenchymal branches of the right pulmonary artery (Figure 2). Concurrent transthoracic echocardiography showed a tripartite homogeneous hyperechogenic mass with a stalk-like structure, measuring $25 \times 27 \mathrm{~mm}$, filling most of the right ventricle, strongly suggestive of a right ventricular thrombus (Figure 3). The right ventricular pressure was within normal limits, thereby excluding pulmonary hypertension. Doppler ultrasound of lower extremities was unremarkable.

Laboratory results were as follows: erythrocyte sedimentation rate: $96 \mathrm{~mm} /$ hour, hemoglobin: $8.01 \mathrm{~g} / \mathrm{dL}$, white blood cell: $17,500 / \mathrm{mm}^{3}$, platelet: $447 \times 10^{3} / \mu \mathrm{L}$, activated partial thromboplastin time: 34 seconds, prothrombin time: 15.9 seconds, activity 67\%, international normalized ratio: 1.3, plasma fibrinogen: $462 \mathrm{mg} / \mathrm{dL}$ (200-400),
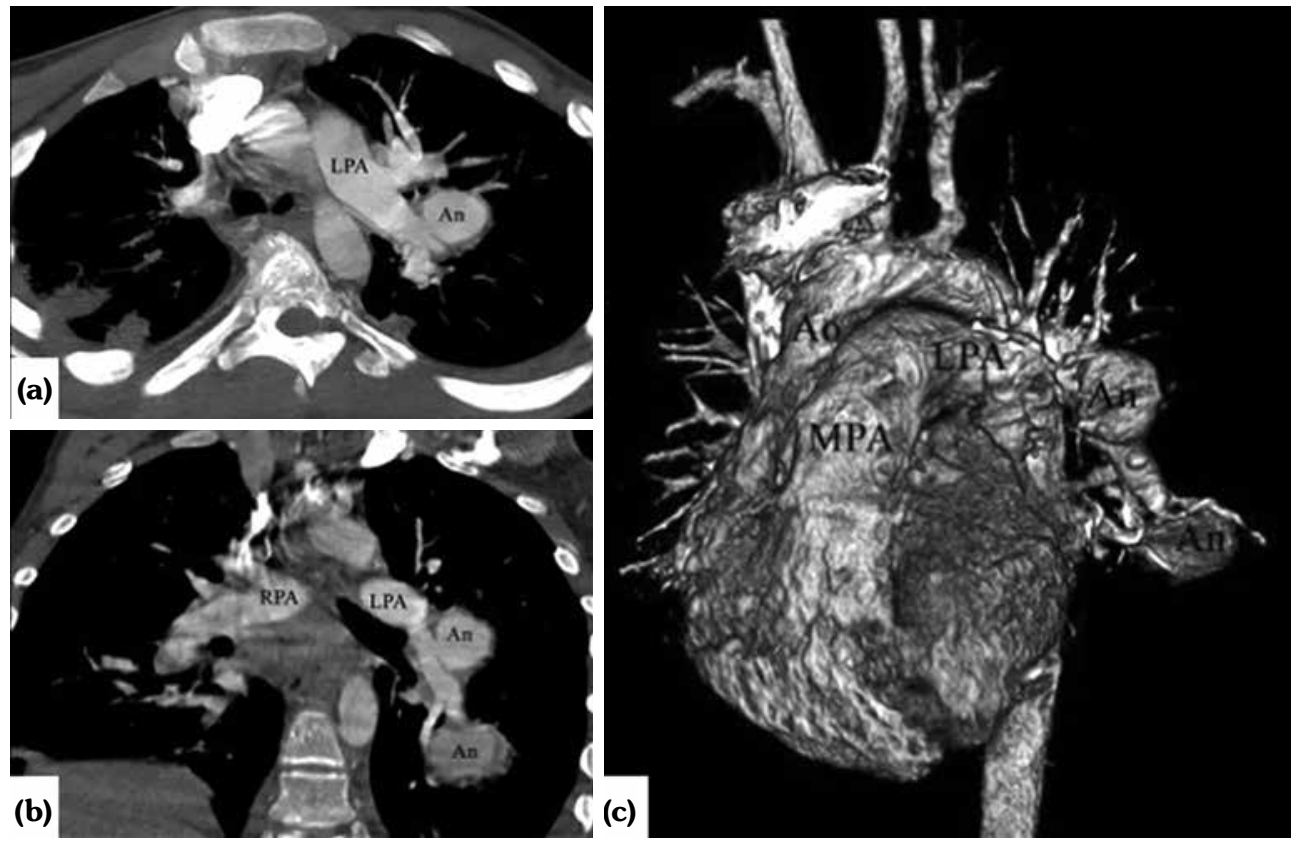

Figure 2. (a) Axial maximum intensity projection. (b) Coronal multiplanar reformatted images. (c) Three dimensional volume rendering showing left pulmonary artery aneurysms and bilateral peripheral infarct areas.

LPA: Left pulmonary artery; An: Aneurysm; RPA: Right pulmonary artery; Ao: Aorta; MPA: Main pulmonary artery. 


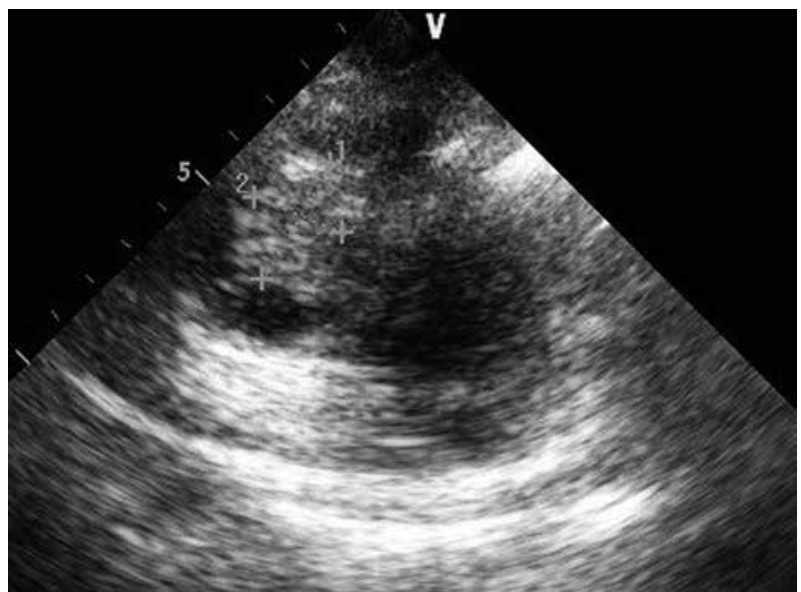

Figure 3. Transthoracic echocardiography showing a tripartite, homogeneous, hyperecogenic mass with a stalk like structure, filling most of right ventricle, strongly suggestive of a right ventricular thrombus.

D-dimer: $1.68 \mathrm{mg} / \mathrm{mL}(<0.5)$, C-reactive protein: $19.9(0-0.8) \mathrm{mg} / \mathrm{dL}$. Protein C, protein S, and other factors were normal. Lupus anticoagulant, antinuclear antibody, anticardiolipin antibody, anti-double stranded deoxyribonucleic acid antibody, prothrombin gene 20210 G-A, and factor $\mathrm{V}$ Leiden mutations were negative. Human leukocyte antigen-B51 and pathergy tests were also negative. $\mathrm{BD}$ was diagnosed based on chronic anterior uveitis, PAA and IcT.

Systemic high dose methylprednisolone followed by $1 \mathrm{mg} / \mathrm{kg}$ intravenous prednisolone for two weeks were given, and then oral prednisolone $16 \mathrm{mg} /$ day was given as maintenance treatment. Cyclophosphamide $\left(1000 \mathrm{mg} / \mathrm{m}^{2}\right.$ monthly) was also administered. Infliximab (5 $\mathrm{mg} / \mathrm{kg})$ was initiated at zero, two, and six weeks and every eight weeks thereafter one week after admission. Since the right ventricular thrombus was large and mobile with a pedunculated structure and there were pulmonary emboli findings despite the presence of multiple pulmonary aneurysms, thrombolytic therapy with tissue plasminogen activator concomitantly with heparin was also started. Anticoagulation was continued with oral warfarin. Although the patient's clinical findings regressed, IcT showed only minor resolution in the acute period. Treatment progressed favorably under a regimen of maintenance doses of methylprednisolone, colchicine, infliximab, cyclophosphamide and warfarin.
A follow-up transthoracic echocardiogram obtained after three months showed significant reduction of the IcT. Chest radiograph showed no regression of PAA. Four months after the initial admission, the patient suddenly died due to massive hemoptysis probably originating from PAA rupture. Since the family rejected autopsy, the precise etiology of death could not be established.

\section{DISCUSSION}

Behçet's disease is a diagnostic challenge due to the lack of any specific test for confirmation. BD classification criteria for pediatric patients were established in $2015 .^{2}$ Due to the features of $\mathrm{BD}$, it may take years for all the common symptoms to appear; the diagnosis is often retrospective. Even though our patient was followed-up for recurrent anterior uveitis, the diagnosis was established only after the development of PAA. Even at that time, he did not fulfill the diagnostic criteria. Rigid use of diagnostic criteria should be abstained in suspected cases without any other causative agent.

Juvenile BD accounts for $1.6-3 \%$ of all cases. Severe systemic manifestations of $\mathrm{BD}$ such as large vessel involvement, pulmonary involvement, and arterial involvement usually affect the young age group ( $<30$ years old) and male sex. ${ }^{4}$ Our case was a 16-year-old male patient who had IcT and pulmonary involvement without deep vein thrombosis. Cardiovascular involvement is infrequent in children with $\mathrm{BD}$; the incidence is approximately 5 to $20 \%$ in pediatric cases. ${ }^{8}$ Pulmonary artery involvement is rare in $\mathrm{BD}$, with reported prevalence rates of lower than $5 \%$. Right-sided IcT is also associated, being present in one-third of patients with pulmonary artery involvement. Besides, pulmonary embolism is extremely rare. ${ }^{9}$ There were PAA accompanying pulmonary emboli and pulmonary artery thrombosis in our case. BD primarily affects the pulmonary arteries in children, and this involvement is usually multifocal and bilateral. Pulmonary parenchymal lesions, pleural effusion, and mediastinal lymphadenopathy can also be detected. 8,10 PAA and cardiac lesions are the major causes of morbidity and mortality in BD. ${ }^{9}$ BD patients with right ventricular thrombi 


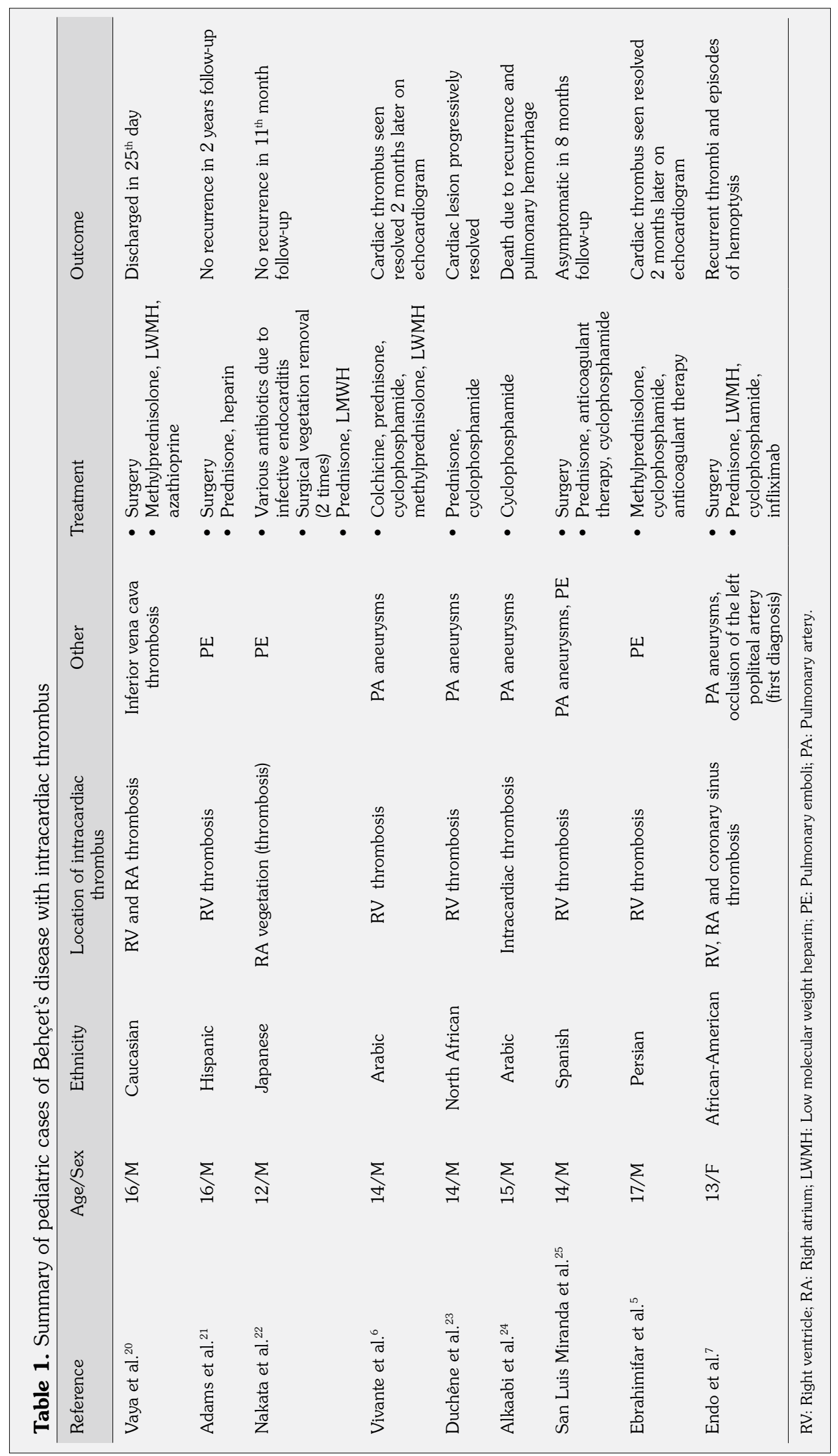


also suffer from pulmonary thromboembolism, which may overlap with pulmonary vasculitis and aneurysm. ${ }^{11}$ For this reason, BD should be suggested in patients with IcT, even in cases without specific clinical symptoms. PAA accompanies IcT in most cases. Thorax CT should be studied to determine the presence of any IcT in such patients. ${ }^{12}$ The common treatment of PAA in BD is mainly with immunosuppressive agents. Since immunosuppressive therapy had encouraging results in BD and surgery had a high risk of mortality, medical therapy was initiated. ${ }^{13}$ Surgery carries a high mortality risk. Even though IcT may be treated with anticoagulant and/or thrombolytic agents, fatal hemoptysis can be seen due to PAA. ${ }^{14}$ There are few reported adult cases in the literature that were treated only with anti-inflammatory drugs to avoid this risky situation. ${ }^{15,16}$ Although the European League against Rheumatism recommendations do not suggest routine anticoagulant use, surveys among $\mathrm{BD}$ experts show that these recommendations do not reflect routine practice. In a survey study, a significant subset of physicians still chose to use anticoagulants as major therapy in vascular BD; anticoagulants were preferred by $87 \%$ of physicians from USA/Israel. ${ }^{17}$ Moreover, a multicenter study showed that anticoagulant use in patients with vascular involvement is preferred by the majority of clinicians in our country. ${ }^{18}$ Nonetheless, treatment protocol for patients with vascular involvement, particularly those with PAA accompanied by thrombosis, has not been clearly defined yet.

Arterial embolization for multiple aneurysms and surgical excision for localized aneurysms are recommended in case of failure or complications in medical treatment. In life-threatening circumstances such as hemoptysis, endovascular interventions may serve as reasonable alternatives. Risk of recurrence is increased in this difficult surgery with arterial fragility. Surgical intervention should be reserved for patients resistant to medical treatment, or those with massive hemoptysis or impaired hemodynamics. Massive recurrent IcT should also be treated surgically. Surgery alone does not lead to a complete resolution and carries recurrence risk. ${ }^{19}$

We searched PubMed/MEDLINE database and Google Scholar with the keywords of
"Behçet's disease" and "intracardiac thrombus" from database inception to 2018. Articles containing pulmonary embolism and pulmonary artery aneurysms were included. The search was restricted to English articles that resulted in nine pediatric cases (Table 1). Only one of the nine patients (11.1\%) was female and the mean age was 14.5 years (range, 12 to 17 years). Thrombi were at the right heart chambers in eight cases (88.8\%). Pulmonary embolism and PAA were accompanying IcT in the majority cases. Five cases were treated surgically (55.5\%). Steroid was used in eight cases (88.8\%), anticoagulant therapy in seven cases (77\%), and cyclophosphamide in five cases (55\%). Azathioprine, colchicine and infliximab were the other used drugs. ${ }^{5-7,20-25}$ Despite all combined treatment options, we could not avoid mortality in our case.

\section{Acknowledgements}

We would like to thank Dr. Kasapcopur and Dr. Vatansever for their guidance and encouragement regarding the patient's treatment.

\section{Declaration of conflicting interests}

The authors declared no conflicts of interest with respect to the authorship and/or publication of this article.

\section{Funding}

The authors received no financial support for the research and/or authorship of this article.

\section{REFERENCES}

1. Criteria for diagnosis of Behçet's disease. International Study Group for Behçet's Disease. Lancet 1990;335:1078-80.

2. Koné-Paut I, Shahram F, Darce-Bello M, Cantarini L, Cimaz R, Gattorno M, et al. Consensus classification criteria for paediatric Behçet's disease from a prospective observational cohort: PEDBD. Ann Rheum Dis 2016;75:958-64.

3. Merashli M, Eid RE, Uthman I. A review of current management of vasculo-Behcet's. Curr Opin Rheumatol 2018;30:50-6.

4. Geri G, Wechsler B, Thi Huong du L, Isnard R, Piette JC, Amoura Z, et al. Spectrum of cardiac lesions in Behçet disease: a series of 52 patients and review of the literature. Medicine (Baltimore) 2012;91:25-34.

5. Ebrahimifar P, Shahabi J. Right ventricular thrombosis as a manifestation of Behçet's syndrome. ARYA Atheroscler 2017;13:91-94. 
6. Vivante A, Bujanover Y, Jacobson J, Padeh S, Berkun $Y$. Intracardiac thrombus and pulmonary aneurysms in an adolescent with Behçet disease. Rheumatol Int 2009;29:575-7.

7. Endo LM, Rowe SM, Romp RL, Buckmaster MA, Atkinson TP. Pulmonary aneurysms and intracardiac thrombi due to Behçet's disease in an AfricanAmerican adolescent with oculocutaneous albinism. Clin Rheumatol 2007;26:1537-9.

8. Topcuoglu OM, Topcuoglu ED, Altay CM, Genc S. Imaging pearls of pediatric Behçet's disease. Eur $\mathrm{J}$ Radiol 2017;94:115-124.

9. Seyahi E, Yazici H. Behçet's syndrome: pulmonary vascular disease. Curr Opin Rheumatol 2015;27:1823.

10. Koné-Paut I. Behçet's disease in children, an overview. Pediatr Rheumatol Online J 2016;14:10.

11. Lisitsyna T, Alekberova Z, Ovcharov P, Volkov A, Korsakova J, Nasonov E. Left ventricular intracardiac thrombus in a patient with Behçet disease successfully treated with immunosuppressive agents without anticoagulation: a case report and review of the literature. Rheumatol Int 2015;35:1931-5.

12. Aksu T, Tufekcioglu O. Intracardiac thrombus in Behçet's disease: four new cases and a comprehensive literature review. Rheumatol Int 2015;35:1269-79.

13. Hatemi G, Silman A, Bang D, Bodaghi B, Chamberlain $\mathrm{AM}$, Gul A, et al. EULAR recommendations for the management of Behçet disease. Ann Rheum Dis 2008;67:1656-62.

14. Canpolat U, Yorgun H, Akdoğan A, Aytemir K. Successful treatment of intracardiac and pulmonary thrombi in Behçet's disease with oral anticoagulant and immunosuppressive therapy. Acta Medica (Hradec Kralove) 2012;55:186-8.

15. Özcan ÖU, Gürlek A, Yıldız G, Akbulut IM, Tutar E, Erol Ç. Management of pulmonary artery aneurysm and intracardiac thrombus in a young male with behçet's disease. Arch Rheumatol 2014;29:318-20.

16. Ben Dhaou B, Ketari S, Boussema F, Aydi Z,
Baili L, Rokbani L. Pulmonary aneurysms in Behçet's disease completely resolved after medical therapy. Rev Pneumol Clin 2012;68:311-4. [Abstract]

17. Tayer-Shifman OE, Seyahi E, Nowatzky J, BenChetrit E. Major vessel thrombosis in Behçet's disease: the dilemma of anticoagulant therapy - the approach of rheumatologists from different countries. Clin Exp Rheumatol 2012;30:735-40.

18. Alibaz-Oner F, Karadeniz A, Ylmaz S, Balkarl A, Kimyon G, Yazc A, et al. Behçet disease with vascular involvement: effects of different therapeutic regimens on the incidence of new relapses. Medicine (Baltimore) 2015;94:e494.

19. Farouk H. Behçet's disease, echocardiographers, and cardiac surgeons: together is better. Echocardiography 2014;31:783-7.

20. Vayá A, Forner MJ, Estellés A, Villa P, Mira Y, Ferrando $F$, et al. Intracardiac thrombosis in a case of Behcet's disease associated with the prothrombin 20210G-A mutation. Haematologica 2000;85:425-8.

21. Adams EE, Aluquin VP, Bingham CA, Stone JR, Pauliks LB. Cardiac tumor in juvenile onset Behçet's disease: case report and review of the literature. Pediatr Cardiol 2010;31:277-9.

22. Nakata Y, Awazu M, Kojima Y, Tokumura M, Yamagishi $\mathrm{H}$, Yamashita N. Behçet's disease presenting with a right atrial vegetation. Pediatr Cardiol 1995;16:150-2.

23. Duchêne F, Berthier $S$, de Wazières $B$, Zyka $F$, Leroy J, Estavoyer JM, et al. Behcet disease with cardiac and pulmonary manifestations. Presse Med 1998;27:1674-6. [Abstract]

24. Alkaabi JK, Pathare A. Pattern and outcome of vascular involvement of Omani patients with Behcet's disease. Rheumatol Int 2011;31:731-5.

25. San Luis Miranda R, Lázaro Castillo JL, Enciso Gómez R, Arias Monroy LG, Ramírez Reyes HA, León Avila JL, et al. Right ventricular thrombous and pulmonary artery aneurysms in Behçet's disease. Report of one case. Arch Cardiol Mex 2007;77:130-6. [Abstract] 